\title{
Malaria parasites (Plasmodium spp.) infecting introduced, native and endemic New Zealand birds
}

\author{
Laryssa Howe • Isabel C. Castro • Ellen R. Schoener • \\ Stuart Hunter • Rosemary K. Barraclough • \\ Maurice R. Alley
}

Received: 21 March 2011 /Accepted: 27 July 2011 /Published online: 14 August 2011

(C) The Author(s) 2011. This article is published with open access at Springerlink.com

\begin{abstract}
Avian malaria is caused by intracellular mosquito-transmitted protist parasites in the order Haemosporida, genus Plasmodium. Although Plasmodium species have been diagnosed as causing death in several threatened species in New Zealand, little is known about their ecology and epidemiology. In this study, we examined the presence, microscopic characterization and sequence homology of Plasmodium spp. isolates collected from a small number of New Zealand introduced, native and endemic bird species. We identified 14 Plasmodium spp. isolates from 90 blood or tissue samples. The host range included four species of passerines (two endemic, one native, one introduced), one species of endemic pigeon and two species of endemic kiwi. The isolates were associated into at least four distinct clusters including Plasmodium (Huffia) elongatum, a subgroup of Plasmodium elongatum, Plasmodium relictum
\end{abstract}

\footnotetext{
L. Howe $(\bowtie)$

Institute of Veterinary,

Animal and Biomedical Sciences, Massey University,

Private Bag 11-222,

Palmerston North 4442, New Zealand

e-mail: L.Howe@massey.ac.nz

I. C. Castro

Ecology Department, Massey University,

Private Bag 11-222,

Palmerston North 4442, New Zealand

E. R. Schoener $\cdot$ S. Hunter $\cdot$ M. R. Alley

New Zealand Wildlife Health Centre, Massey University, Private Bag 11-222,

Palmerston North 4442, New Zealand

R. K. Barraclough

Institute of Natural Sciences, Massey University,

Albany Campus, NSMC Private Bag,

102904 Auckland, New Zealand
}

and Plasmodium (Noyvella) spp. The infected birds presented a low level of peripheral parasitemia consistent with chronic infection (11/15 blood smears examined). In addition, we report death due to overwhelming parasitemia in a blackbird, a great spotted kiwi and a hihi. These deaths were attributed to infections with either Plasmodium spp. lineage LINN1 or P. relictum lineage GRW4. To the authors' knowledge, this is the first published report of Plasmodium spp. infection in great spotted and brown kiwi, kereru and kokako. Currently, we are only able to speculate on the origin of these 14 isolates but consideration must be made as to the impact they may have on threatened endemic species, particularly due to the examples of mortality.

\section{Introduction}

Avian malaria is a mosquito-borne disease caused by intracellular parasites in the order Haemosporida, genus Plasmodium. Species of the genus Plasmodium have a cosmopolitan distribution and can infect nearly all avian taxa (Valkiunas 2005). The use of molecular methods has uncovered a greater genetic diversity and phylogenetic complexity of avian malaria parasites and has resulted in the suggestion that there could be as many species of avian malaria parasites as there are host species (Bensch et al. 2004).

Passerines are known to be hosts to the largest number of haemosporidian parasites (Valkiunas 2005). For example, Plasmodium relictum has a worldwide distribution and has long been known to infect blackbirds (Turdus merula) and other introduced birds in New Zealand (Dore 1920; Laird 1950; Tompkins and Gleeson 2006), but there are no reports of mortality in introduced birds due to Plasmodium spp. in this country. Tompkins and Gleeson (2006) found a high prevalance of Plasmodium spp. in introduced passerines 
depending on region and time of year. Introduced birds are commonly seen as asymptomatic carriers of avian malaria, showing a low mortality and mainly chronic parasitemia of malaria (Tompkins and Gleeson 2006).

Over the last decade, avian malaria has aroused increasing interest in New Zealand with some endemic avian species, such as the endangered mohua (Mohua ochrocephala), thought to be particularly susceptible to Plasmodium spp. infection (Alley et al. 2008; Derraik et al. 2008). Recently, Castro et al. (2011) have described chronic infections involving three Plasmodium isolates belonging to at least two clades (Plasmodium (Huffia) elongatum and Plasmodium (Haemamoeba) relictum) and reported their seasonal prevalence in North Island saddlebacks. A Plasmodium sp. has also been diagnosed as causing death in threatened species such as dotterel (Charadrius obscurus) (Alley 2002), South Island saddleback (Philesturnus carunculatus carunculatus) (Alley et al. 2010) and mohua (Alley et al. 2008), but little is known about Plasmodium spp. ecology and epidemiology

We have only limited morphometric and phylogenetic descriptions of avian malaria lineages in New Zealand as well as information regarding their origin and virulence. Based on the suggested diversification of avian haemosporidian parasites at approximately 20 million years ago (Ricklefs et al. 2004; Ricklefs and Outlaw 2010), the endemic nature of many of New Zealand's avifauna and its geographical isolation, it is likely that at least some lineages of avian malaria are endemic to New Zealand birds. The possible endemic nature of some New Zealand malarial lineages is supported by the high prevalence of chronic infection, relatively stable bird communities and the presence of endemic mosquito vectors (Jarvi et al. 2003). Tompkins and Gleeson (2006) proposed that because both the endemic mosquitoes are increasing in abundance and the exotic mosquito species are spreading, there is great potential for avian malaria to amplify its impact on New Zealand native birds. In addition, malarial lineages from introduced host species may be outcompeting yet unidentified native malaria species. The effects of these blood parasites could be detrimental to native birds if they evolved lacking exposure to particular malaria lineages (Bennett et al. 1993).

Hence, this current study was designed to be an investigation to determine if infection is occurring and which species of the genus Plasmodium are circulating among New Zealand avian species. In this study, we examined three introduced, two native and seven endemic avian species for the presence of Plasmodium spp. Each Plasmodium isolate was characterized using molecular methods and microscopically (where possible) and compared to previously characterized Plasmodium lineages. The results of this study provide both initial information on host specificity and the potential endemic or introduced origin of the parasite as well as an indication of possible transmission pathways. This knowledge is important to New Zealand and is the first step in developing a phylogeographical database that will be useful in predicting and managing avian malaria disease impacts.

\section{Methods}

Bird capture sites

The birds used in this study were captured or collected during 2007-2009 at several locations in New Zealand as follows: blackbird (T. merula, $n=1$ ), song thrush (Turdus philomelos, $n=1$ ), chaffinch (Fringilla coelebs, $n=1$ ), tui (Prosthermadera novaeseelandiae, $n=18$ ), North Island robin (Petroica longipes, $n=27$ ) and fantail (Rhipidura fulginosa, $n=4$ ) were captured using standard mist-netting techniques on Mokoia Island, Lake Rotorua, North Island $\left(38^{\circ} 04^{\prime} \mathrm{S} 176^{\circ} 17^{\prime} \mathrm{E}\right)$ during $2007-2008$ as described by Castro et al. (2011). North Island kokako (Callaeas cinerea wilsoni) $(n=8)$ were captured at Rotoehu forest, Bay of Plenty, North Island $\left(37^{\circ} 59^{\prime} \mathrm{S} 176^{\circ} 30^{\prime} \mathrm{E}\right)$ in 2009 as part of a translocation project to Secretary Island, Fiordland Coast, South Island $\left(45^{\circ} 14^{\prime} \mathrm{S} 166^{\circ} 56^{\prime} \mathrm{E}\right)$ by the New Zealand Department of Conservation (Megan Willans, personal communication). Brown kiwi (Apteryx mantelli) $(n=10)$ were sampled on Ponui Island $\left(36^{\circ} 55^{\prime} \mathrm{S}, 175^{\circ} 11^{\prime} \mathrm{E}\right)$ in 2004 as part of another study where they were caught at night with the help of trained kiwi dogs. Additional birds were sampled from the greater Auckland area as part of a larger study and included a native silvereye (Zosterops lateralis) mist-netted at Massey University, Albany Campus $\left(36^{\circ} 43^{\prime} \mathrm{S} 174^{\circ} 42^{\prime} \mathrm{E}\right)$ in 2007 , blackbirds $(n=2)$ mist-netted on Tiritiri-Matangi Island and a kereru/wood pigeon (Hemiphage novaeseelandiae) sampled at Birdwing, Rothesay Bay, 2008. Finally, blackbirds $(n=3)$ and hihi/ stitchbird (Notiomystis cincta) $(n=10)$ were captured in 2008 by mist-netting at Ark in the Park in the Waitakere Ranges, North Shore, North Island (36 $55^{\prime}$ S $174^{\circ} 29^{\prime}$ E).

Blood collection and smear preparation

Blood sampling for all captured passerines was performed as described by Castro et al. (2011). Blood samples from kiwi were collected by venipuncture of the tibio-tarsal vein directly into a heparinised syringe.

Two drops of blood from most birds sampled were used to produce thin blood smears which were air-dried and fixed in absolute methanol at the time of collection and subsequently stained with Giemsa (diluted 1:10 for 45-60 min). All eight kokako blood smears were examined; 
however, only blood smears from the nine remaining PCRpositive birds were examined by microscopy in order to determine the Plasmodium spp. and whether co-infection was present. Each smear was examined under a light microscope for a minimum of $15 \mathrm{~min}$, initially at low power $(\times 200)$ for $3 \mathrm{~min}$ then $\times 1,000$ under oil immersion. However, thin blood smears from kokako were examined longer, $3 \mathrm{~min}$ at $\times 200$ then for a minimum of $3 \mathrm{~h}$ at $\times 1,000$ oil immersion. The observed blood parasites were photographed.

The remaining blood was combined with Seutin's buffer and kept at $4^{\circ} \mathrm{C}$ until taken to the laboratory where they were stored at $-20^{\circ} \mathrm{C}$. Samples from brown kiwi were separated into serum and cells. The cell component was frozen at $-20^{\circ} \mathrm{C}$.

\section{Pathological studies}

In February 2009, a juvenile female blackbird was found freshly dead (showing rigor mortis) near the camp site on the eastern side of Mokoia Island $500 \mathrm{~m}$ from the jetty. Necropsy was performed on location and no gross abnormalities were observed. Tissues from a full range of organs were fixed in $10 \%$ buffered formalin for histopathology and molecular studies.

In addition, two other dead birds, a great spotted kiwi (Apteryx haastii) from a breeding programme in Rangiora, Northern Canterbury $\left(43^{\circ} 18^{\prime} \mathrm{S} 172^{\circ} 35^{\prime} \mathrm{E}\right)$ and a juvenile hihi recently translocated to Tiritiri Matangi Island, Hauraki Gulf $\left(36^{\circ} 35^{\prime} \mathrm{S} 174^{\circ} 53^{\prime} \mathrm{E}\right)$, were submitted to Massey University Wildlife Health Centre by the New Zealand Department of Conservation for necropsy. Tissues from lung, liver, spleen, heart, brain, skeletal muscle and kidney were fixed in $10 \%$ buffered formalin for histopathology or frozen for molecular studies.

All fixed tissues were routinely processed, embedded in paraffin, cut at $3 \mu \mathrm{m}$ and stained with haematoxylin and eosin.

DNA extraction, PCR amplification and sequencing

DNA was extracted from paraffin-embedded, fixed liver tissue or frozen whole blood mixed in Seutin's buffer or frozen cells using a Qiagen DNeasy Kit (Qiagen, Valencia, CA, USA) following the manufacturer's instructions for paraffin-embedded or nucleated whole blood, respectively. The presence of the cytochrome $b$ gene of Plasmodium spp. was identified using a nested PCR and the nested primer sets HaemNF1/HaemNR3 and HaemF/HaemR2 as described by Hellgren et al. (2004). To confirm a successful amplification, $10 \mathrm{ul}$ of the final PCR product was run on a $1.5 \%$ agarose gel containing ethidium bromide prior to purification and sequencing. A known Plasmodium spp.-positive blood sample was used as a positive control and water blanks were included as negative controls.

All Plasmodium spp.-positive PCR amplicon samples were purified using a PureLink PCR purification kit (Invitrogen, Carlsbad, CA, USA) and subjected to automatic dye-terminator cycle sequencing with BigDye ${ }^{\mathrm{TM}}$ Terminator Version 3.1 Ready Reaction Cycle Sequencing kit and the ABI3730 Genetic Analyzer (Applied Biosystems Inc, Foster City, CA, USA) to confirm genomic sequence using both the forward and reverse primers. Chromatograms were examined for conspicuous overlapping peaks suggestive of Plasmodium spp. co-infection. The Plasmodium isolate sequences obtained were compared to the MalAvi database (Bensch et al. 2009) and by NCBI Blast to those other published sequences available from GenBank. The resulting sequences were submitted to the Genbank database (HQ453994-HQ454003).

\section{Phylogenetic analysis}

The 14 mitrochondrial cytochrome $b$ sequences from our survey and 21 sequences for the MalAvi and GenBank databases, including representatives of the $P$. (Huffia) elongatum, P. (Haemamoeba) relictum and P. (Novyella) spp. lineages as proposed by Valkiunas et al. (2008b, 2009) were trimmed to the same length (450 bases) using Geneious $^{\mathrm{TM}}$ (Biomatters, Auckland, New Zealand) and aligned using Clustal W (Higgins et al. 1994).

A phylogenetic tree was generated in MrBayes version 3.1 (Ronquist and Huelsenbeck 2003) using Bayesian phylogenetics. A general time-reversible model including invariable sites $(\mathrm{GTR}+\mathrm{I})$ was used. The Bayesian phylogeny was obtained using one cold and three hot Monte Carlo Markov chains, which were sampled every 1,000 generations over five million generations; 5,000 trees were generated. Of these trees, $25 \%$ were discarded as burn-in material. The remaining 3,750 trees were used to construct a majority consensus tree. In addition, a Jukes-Cantor distance model and neighbour-joining method were performed in Geneious ${ }^{\mathrm{TM}}$ using the trimmed Clustal $\mathrm{W}$ alignment. Bootstrap values were generated from 1,000 cycles. Bootstrap percentages from the neighbour-joining analysis were added to the tree at the appropriate nodes.

The sequence divergence between and within the different lineages was calculated using a Jukes-Cantor model of substitution implemented in the programme PAUP* 4.0 Beta version 10 (Swofford 2002).

Ethics, approval and permits

Samples from different sites were collected under different permits as follows: Mokoia Island: Massey University Animal Ethics 06/111 NZ Dept Conservation permit 
BP-22693-RES/BP-23988-RES and NZ Banding Office 2006/85. Samples collected in the greater Auckland area: Massey University Animal Ethics 09/43, NZ Dept Conservation permit AK-20666-FAU, and NZ Banding Office 2008/33. Samples from Ponui Island: Massey University Animal Ethics 04/33, NZ Dept Conservation permit AK/14970/RES.

\section{Results}

Bird capture and manipulations

We collected and examined 87 blood samples from 12 species in three different avian orders (Table 1). Three of the nine species were classified as introduced to New Zealand, two species are native by self-introduction and the remaining seven species are endemic to New Zealand.

Molecular studies

A total of 11 blood samples were positive for the presence of Plasmodium spp. and included samples from six blackbirds, one silvereye, two kokako, one kereru and one North Island brown kiwi (Table 1). In addition, liver tissues from the dead blackbird, hihi and great spotted kiwi were also positive for Plasmodium spp. by PCR (Table 1). None of the remaining samples collected were positive for the presence of Plasmodium spp. DNA (Table 1).
All 14 Plasmodium spp.-positive PCR products had sufficient amplification to be sequenced. The resulting chromatograms did not reveal any evidence of mixed infections (conspicuous overlapping peaks) and were submitted for BLAST analysis to compare the isolates against the NCBI GenBank database. The results revealed six lineages of Plasmodium spp. present in the bird examined (Table 1). When considered together, the phylogenetics and the divergence results suggested four distinct clusters among the 14 Plasmodium spp. isolates (Fig. 1).

The first group (cluster A) included the blackbird \#1, silvereye and brown kiwi isolates and clustered with previously identified New Zealand isolates from the North Island saddleback NISB1 and NISB2 (GenBank GU552450 and GU552451) and South Island saddleback (GenBank GU552449) (Fig. 1). All of the isolates in cluster A had $100 \%$ sequence homology to previously published and well-characterized lineages of $P$. (Huffia) elongatum from a great blue heron (Ardea herodias) (GenBank DQ659588) and pGRW06 from a great reed warbler (Acrocephalus arundinaceus; GenBank DQ368381) (Fig. 1). A search within the MalAvi database, which includes unpublished lineage and sequence data, revealed that the pGRW06 lineage has been detected previously in New Zealand passerines such as blackbirds, song thrush (T. philomelos), sparrow (Passer domesticus), yellowhammer (Emberiza citronella), whitehead (Mohoua albicilla) and robin (Petroica australis).

Cluster B comprised a New Zealand isolate from the blackbird \#2 found on Mokoia Island and the great spotted

Table 1 Avian species and number of samples collected during 2007-2009 and number of lineages of Plasmodium spp. within each avian species sampled

\begin{tabular}{|c|c|c|c|c|c|c|c|c|}
\hline \multirow[t]{2}{*}{ Order } & \multirow[t]{2}{*}{ Family } & \multirow{2}{*}{$\begin{array}{l}\text { Common name } \\
(\mathrm{I}, \mathrm{E}, \mathrm{N})\end{array}$} & \multicolumn{3}{|c|}{ Number sampled } & \multirow{2}{*}{$\begin{array}{l}\text { Number } \\
\text { positive by PCR }\end{array}$} & \multirow{2}{*}{$\begin{array}{l}\text { Number positive } \\
\text { by microscopy }\end{array}$} & \multirow{2}{*}{$\begin{array}{l}\text { Number of } \\
\text { lineages identified }\end{array}$} \\
\hline & & & Blood & Tissue & Total & & & \\
\hline \multirow[t]{9}{*}{ Passeriformes } & Turdidae & Blackbird (I) & 6 & 1 & 7 & $7 / 7$ & $5 / 5$ & 4 \\
\hline & Fringillidae & Chaffinch (I) & 1 & 0 & 1 & $0 / 1$ & ND & 0 \\
\hline & Turdidae & Song thrush (I) & 1 & 0 & 1 & $0 / 1$ & ND & 0 \\
\hline & Rhipiduridae & Fantail (N) & 4 & 0 & 4 & $0 / 4$ & ND & 0 \\
\hline & Zosteropidae & Silvereye $(\mathrm{N})$ & 1 & 0 & 1 & $1 / 1$ & $1 / 1$ & 1 \\
\hline & Petroicidae & NI Robin (E) & 27 & 0 & 27 & $0 / 27$ & ND & 0 \\
\hline & Meliphagidae & Tui $(\mathrm{E})$ & 18 & 0 & 18 & $0 / 18$ & ND & 0 \\
\hline & Notiomyslidae $^{\mathrm{a}}$ & Hihi (stitchbird) (E) & 10 & 1 & 11 & $1 / 11$ & ND & 1 \\
\hline & Callaeidae. & Kokako (E) & 8 & 0 & 8 & $2 / 8$ & $2 / 8$ & 1 \\
\hline Columbiformes & Columbidae & Kereru (woodpigeon) (E) & 1 & 0 & 1 & $1 / 1$ & $1 / 1$ & 1 \\
\hline \multirow[t]{3}{*}{ Struthioniformes } & Apterygidae & Brown kiwi (E) & 10 & 0 & 10 & $1 / 10$ & ND & 1 \\
\hline & Apterygidae & Great spotted kiwi (E) & 0 & 1 & 1 & $1 / 1$ & ND & 1 \\
\hline & & Total & 87 & 3 & 90 & $14 / 90$ & $11 / 15$ & 6 \\
\hline
\end{tabular}

$I$ introduced into New Zealand by humans and/or their activities, $E$ endemic birds only found in New Zealand, $N$ native birds that are naturally found in New Zealand or are self-introduced (Heather and Robertson 2005), ND not done

${ }^{a}$ Family recently renamed (Driskell et al. 2007) 
Fig. 1 Phylogenetic analysis and comparison of 14 Plasmodium spp. isolates from New Zealand avian species and previously published Plasmodium spp. sequences present in the GenBank and/or MalAvi database. Bayesian and neighbour-joining $(N J)$ phylogeny of mitochondrial cytochrome $b$ gene from Plasmodium falciparum used as an outgroup, 20 previously published Plasmodium spp. submitted to Genbank or the MalAvi database and the 14 Plasmodium spp. New Zealand isolates (in bold font) from this study. Lineages of malaria parasites which are closely related (within a genetic distance of $\leq 5 \%$ ) to $P$. (Huffia) elongatum, P. (Haemamoeba) relictum and $P$. (Novyella) spp. are marked by bars $A, C$ and $D$ to represent the different subgenera. The bar $B$ indicates a possible subgroup of Plasmodium elongatum. Numbers above or below branch nodes indicate bootstrap support based on 1,000 replicates. Names of the lineages (when available) and Genbank accession numbers of the sequences are given after the species names of the parasites. The branch lengths are drawn proportionally to the amount of changes (scale bar is shown)

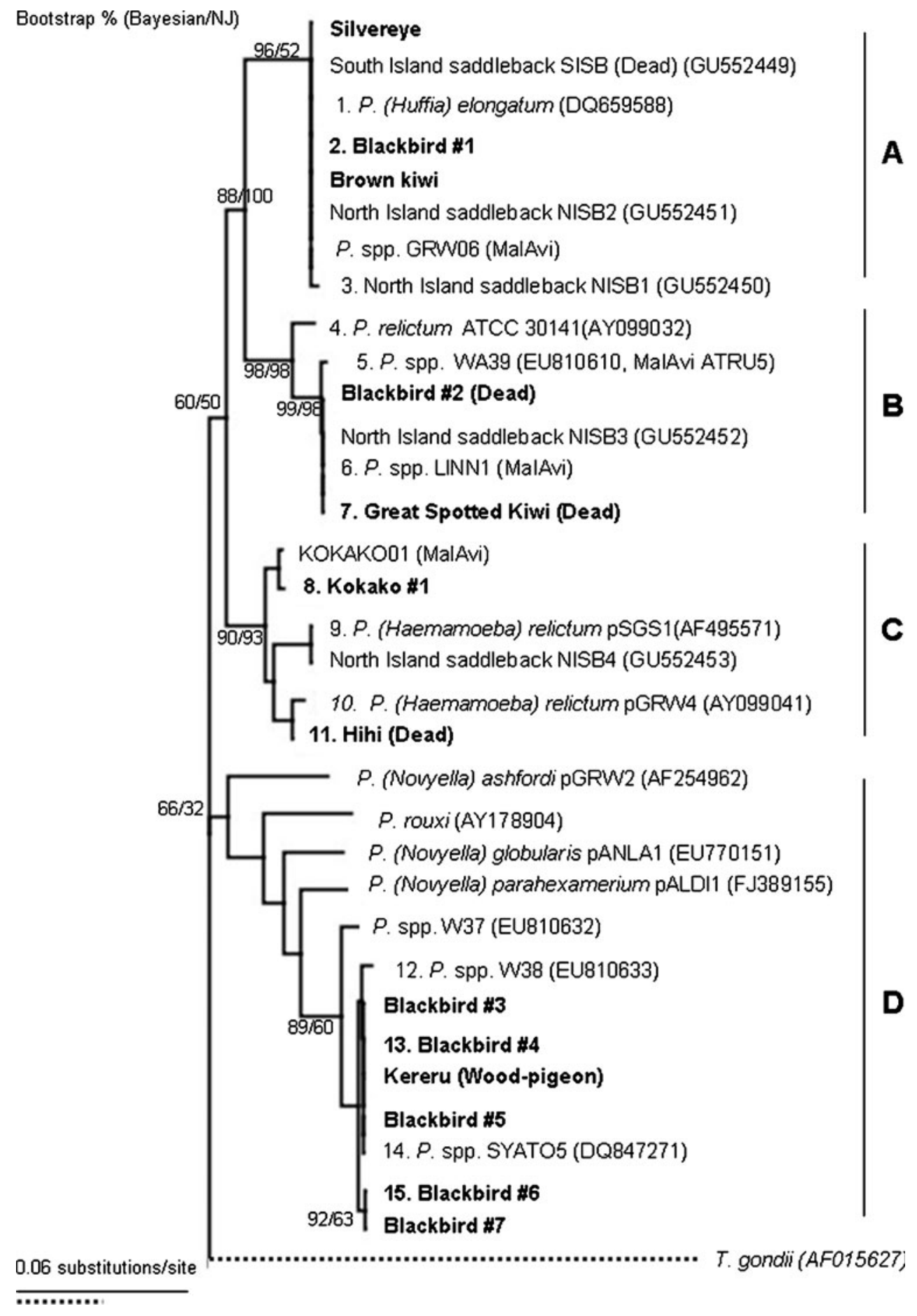

kiwi from the South Island. Both of these isolates had $100 \%$ sequence homology with another Plasmodium spp. lineage, NISB3, from a North Island saddleback (GenBank GU552452) (Fig. 1). Sequence homology to other published sequences included $100 \%$ to a Plasmodium sp. from Culex pipiens in the USA (GenBank GQ471953) and lineage LINN1 originally isolated from a French blackbird (MalAvi database) but also detected in a New Zealand in the bellbird (Anthornis melanura), blackbird and song- thrush (MalAvi database). In addition, our isolates had $99 \%$ sequence homology to a lineage W39 from an African thrush (Turdus pelios; GenBank EU81610, MalAvi AFTRU5) and 98\% homology to a $P$. relictum ATCC 30141 lineage from a mourning dove (Zenaida macroura; GenBank AY099032) (Fig. 1). The sequence divergence was calculated to be $0.0 \%$ between the blackbird \#2, great spotted kiwi, Plasmodium spp. NISB3 and LINN1 lineages and $0.2 \%$ compared to the W39 lineage. Considered 
together, cluster B appears to be closely related to the $P$. (Huffia) elongatum cluster A, suggesting that despite containing a lineage named $P$. relictum, this cluster may in fact be a subgroup of cluster A (Fig. 1).

Higher sequence variation and divergence was observed between the two kokako and the dead hihi isolates comprising cluster C (Fig. 1). The Plasmodium spp. isolates from the hihi and kokako had $99 \%$ and $98 \%$ sequence homology, respectively, to $P$. (Haemamoeba) relictum lineages such as pGRW4 (GenBank AY099041) from a Eurasian great reed warbler and detected in a New Zealand sparrow (MalAvi database) (Fig. 1). The kokako isolates closely aligned to a lineage KOKAKO01 isolated from a kokako and recorded in the MalAvi database. In addition, the kokako and hihi isolates where different from the North Island saddleback Plasmodium lineage NISB4 (GenBank GU552453), which had $100 \%$ sequence homology to a different Plasmodium spp., in particular P. (Haemamoeba) relictum lineage pSGS1 from a golden sparrow (Passer luteus; GenBank AF495571) (Fig. 1). NaturalLY occurring infections of lineage pSGS1 have also been detected in New Zealand infecting a sparrow, yellowhammer and myna (Acridotheres tristis) (MalAvi database). Moreover, the kokako isolate had $1.6 \%$ sequence divergence when compared to the hihi isolate, $2.0 \%$ divergence with lineage GRW4 and a $2.2 \%$ divergence with the $P$. relictum pSGS1 and North Island saddleback Plasmodium NISB4 lineage clustered within the same group.

Cluster D included the majority (71\%) of the blackbird isolates and the isolate from the kereru and grouped with well-characterized lineages of the subgenus Novyella (Fig. 1). Blackbird isolates \#3, 4 and 5 and the kereru isolate all had $100 \%$ sequence homology with the published Plasmodium spp. lineage SYATO5 (GenBank DQ847271) detected in New Zealand blackbirds and tomtit (Petroica macrocephala) (MalAvi database), whilst blackbird isolates $\# 6$ and \#7 had 99\% homology. Sequence divergence analysis revealed $0.2 \%$ divergence between blackbird isolate \#4 and the other two blackbird isolates (\#6 and \#7). Sequence database results show that the kereru and blackbird isolates clustered with Plasmodium lineages collected from members of the Turdidae family such as the African thrush (T. pelios) lineage W38 (GenBank EU810633, MalAvi AFTRU08) at 99\% homology and W37 (GenBank EU810632, MalAvi AFTRU4) at $98 \%$ homology. Cluster D was also the most divergent (7.3-8.4\%) when compared across the four cluster groups.

The sequence divergence between clusters $\mathrm{A}, \mathrm{B}$ and $\mathrm{C}$ was similar between groups ranging from $5.1 \%$ to $8.0 \%$. The only exception was $P$. relictum ATCC 30141 from cluster B which had a sequence divergence of $4.7 \%$ when compared to the P. (Huffia) elongatum cluster, strongly suggesting that cluster B is a subgroup of cluster A rather than a separate subgenus as observed between the remaining three clusters.

Microscopic examination of blood smears

Thin blood smears from one kereru, eight kokako, five blackbirds and one silvereye were examined (Table 1). Parasites were not always detected in the thin blood smears of infected birds nor were all developmental stages represented when parasites were seen. Parasites were observed in 2/12 kokako, the silvereye and 4/5 blackbirds. No parasites were seen in the kereru blood smear and insufficient examples of parasites from the kokako in cluster C (Fig. 2a, b) were available to allow identification. However, $P$. elongatum was identified within the silvereye (not shown) and P. (Novyella) rouxi was identified from a blackbird in cluster D (Fig. 2c, d). No mixed infections were observed.

\section{Pathological studies}

Tissues from the dead blackbird $\# 2$, hihi and great spotted kiwi were examined histologically. In the blackbird and great spotted kiwi, capillary endothelial cells in all the tissues examined were affected. These cells were often enlarged and the cytoplasm was filled with numerous small basophilic granular structures resembling protozoal merozoites. Each organism measured about $2-3 \mu \mathrm{m}$ in diameter, was slightly elongated and separated from one another. The endothelial cell nucleus was often crescent-shaped because of compression to one end of the cell by the intracytoplasmic meront (Fig. 3a-f). In the blackbird, the organisms were particularly numerous in the brain (Fig. 3a), lung (Fig. 3b) and heart. All birds showed a mild to moderate diffuse interstitial pneumonia with thickening of the pulmonary interstitium by infiltrating mononuclear cells. There was sequestration of occasional heterophils and collapse of some air capillaries in the blackbird and hihi (Fig. 3b, f) and increased numbers of pulmonary macrophages in the great spotted kiwi (Fig. 3d). The livers of the three birds showed a moderate multifocal hepatitis with mononuclear cells and haematopoetic cells accumulating around portal areas. There was mild haemosiderin deposition in hepatocytes and Kupffer cells as well as within histiocytes of the spleen. In the great spotted kiwi, the spleen also showed multifocal areas of fibrinoid necrosis at the margin of which macrophages containing intracytoplasmic merozoites were visible. The thymus and bursa of both the great spotted kiwi and blackbird, however, were active with many lymphocytes present. The ventricular myocardium in both of these birds showed eosinophilic degeneration of some fibres with swelling, fragmentation and vacuolation of sarcoplasm and occasional intracytoplasmic meronts present 
Fig. 2 Representative develop mental structures observed in the erythrocytes from two bird species demonstrating distinct Plasmodium subgenus morphologies. $t$ trophozoites, $m g$ macrogametocyte, $s$ intraerythrocytic schizont/ meront. a, b Kokako \#1 erythrocytes suggestive of $P$. (Haemomoeba) relictum. c, $\mathbf{d}$ Blackbird \#3 erythrocytes infected with $P$. (Novyella) spp. suggestive of $P$. rouxi. Scale bars $=10 \mu \mathrm{m}$

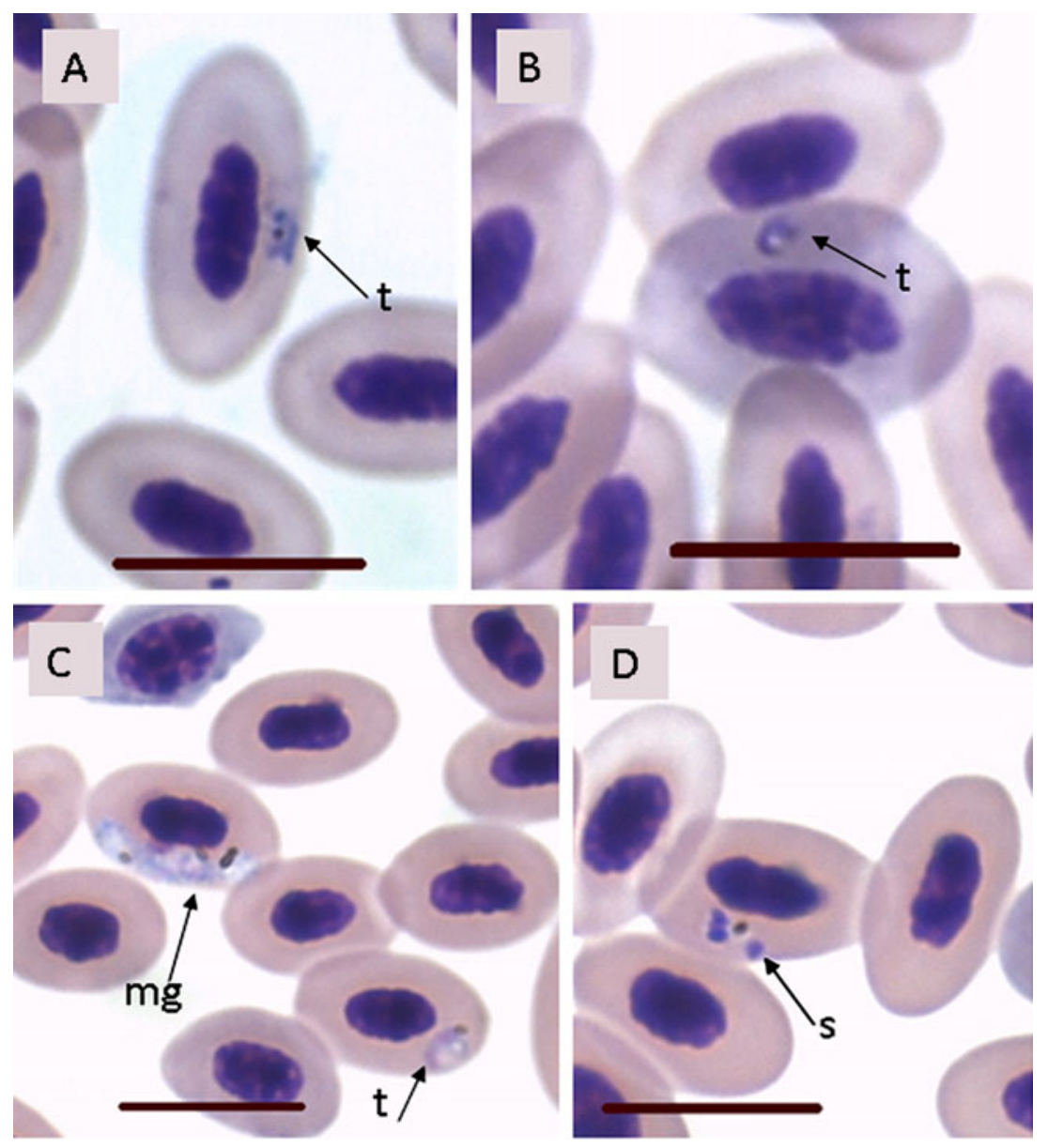

in adjacent capillary endothelial cells. Taken together, the clinical history of the hihi and great spotted kiwi and the histopathological findings in all three birds are highly suggestive of death from acute Plasmodium spp. infection.

\section{Discussion}

This current study was designed to be an investigation to determine if Plasmodium spp. infection is occurring and which species are circulating among New Zealand avian species. The results of this study revealed at least four different Plasmodium spp. clusters with six distinct lineages circulating through several New Zealand bird species. In addition, death due to acute Plasmodium spp. infection was reported in the hihi, great spotted kiwi and blackbird. To the authors' knowledge, this is the first published report of Plasmodium spp. infection in great spotted and brown kiwi, kereru and kokako.

P. (Huffia) elongatum has been reported in a wide range of avian orders, including waterfowl (Aneriformes), raptors (Falconiformes), owls (Strigiformes) and particularly Passeriformes which are considered to act as reservoirs (Valkiunas 2005). Our findings support the suggestion made by Castro et al. (2011) that lineages of P. (Huffia) elongatum, such as pGRW06, may have been in New Zealand for a long time. It appears to be endemic in the population due to the wide host diversity of infection, apparent chronic nature of disease and a variety of potential endemic mosquito vectors, particularly in the North Island where the climate has generally been more favourable. A similar pattern has been observed in American Samoa among native land birds (Jarvi et al. 2003). This, however, does not restrict the potential impact of indigenous Plasmodium species where naïve hosts, new lineages or vectors, or immunosuppressive agents, such as avian pox virus, could destabilize the system. An example of such a destabilization event was observed when a group of South Island saddlebacks were translocated and the combination of stress, avian pox virus and P. elongatum infection resulted in a significant mortality event (Alley et al. 2010).

There are 16 species of mosquito present in New Zealand, 12 are endemic and four introduced (Derraik 2004). With the exception of $C$. pervigilans, native mosquitoes tend to have restricted ranges and are thought to feed primarily on the blood of birds. A Plasmodium sp. isolated from a $C$. pervigilans blood-engorged female suggests that these species could also be vector of avian 
Fig. 3 Haematoxylin-and-eosinstained tissues from the dead blackbird (a cerebellum, b lung), great spotted kiwi (c spleen, d lung) and hihi (e spleen, f lung). Arrows indicate areas containing Plasmodium spp. schizonts. $\times 100$ magnification. Scale bars $=20 \mu \mathrm{m}$
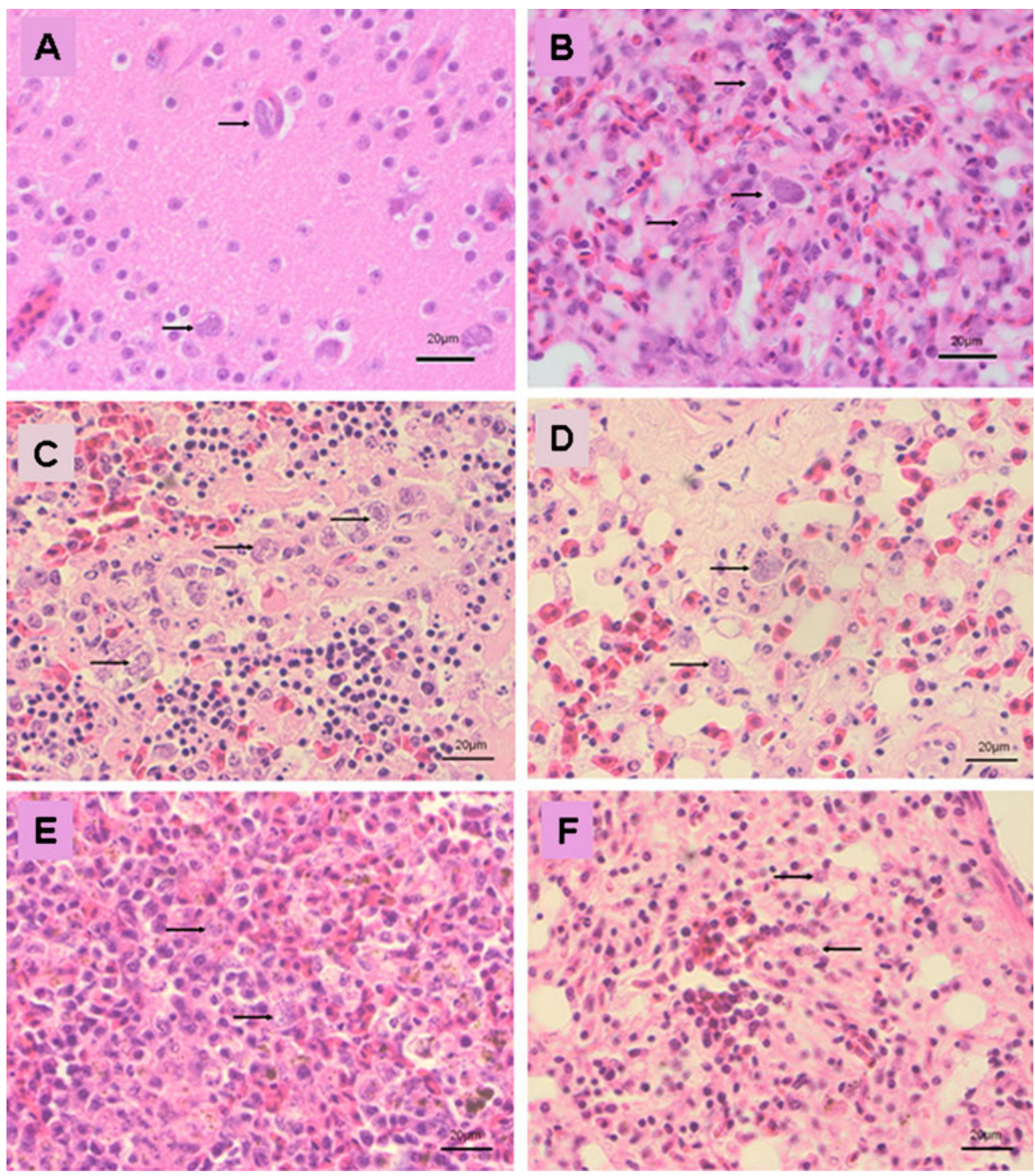

malaria (Massey et al. 2007). The mosquito Culex quinquefasciatus has also been identified in New Zealand and over the last 30 years has extended its distribution from the North Island regions of Northland and Auckland, the site of original introduction, to the Canterbury region of the South Island (Tompkins and Gleeson 2006). This is of particular concern as this vector is generally considered to be responsible for the avian malaria infections which have caused the decline in native avifauna in Hawaii (LaPointe et al. 2005).

Based on the results presented in this study, it is possible that the lineages within cluster $\mathrm{B}$ may be a subgroup of $P$. elongatum instead of a subgroup of $P$. relictum. This is supported by $P$. relictum ATCC 30141, the more distant member of the group, having a sequence divergence of less than $5 \%$ when compared to P. (Huffia) elongatum. Recent studies have suggested that Plasmodium lineages with a cytochrome $b$ divergence of over 5\% are expected to be morphologically differentiated (Valkiunas et al. 2010; Hellgren et al. 2007; Valkiunas et al. 2009). In addition,
Valkiunas et al. (2008a) have established that GenBank contains many taxonomically misidentified lineages, of which P. relictum ATCC 30141 is one. Unfortunately, we were unable to observe sufficient examples of parasites in this cluster via microscopy to aid in the determination.

Information on the pathogenicity, prevalence and host/ vector range is also limited for members of cluster B. However, lineage WA39 within this subgroup has demonstrated a high level of specificity at the avian host family level (Beadell et al. 2009) and a high level of host sharing between the Culex vectors (Kimura et al. 2009). In contrast, we have found closely related lineages of this parasite infecting avian groups as distant as great spotted kiwi, North Island saddlebacks and blackbirds. It is important to note the apparent pathogenicity of this isolate extracted from the dead blackbird and great spotted kiwi which had a pathology consistent with extensive acute parasitemia.

Within cluster C, P. relictum lineages GRW4 and SGS1 are widespread throughout Europe and tropical Africa, are 
host generalists and are cosmopolitan in their distribution (Valkiunas 2005). At least 29 species have been identified from 13 (GRW4) or eight (SGS1) different avian families (Palinauskas et al. 2007; Waldenstrom et al. 2004; Beadell et al. 2006; Hellgren et al. 2007). In addition, lineages GRW4 and SGS1 have been shown to infect multiple African and European avian host species, which suggests that members of the $P$. (Haemamoeba) relictum subgenera undergo relatively frequent host shifts particularly during migration events (Hellgren et al. 2007; Waldenstrom et al. 2004). Notably, the ability to host shift may have contributed to the decline and extinction of bird species in Hawaii after the introduction of lineage GRW4 (Beadell et al. 2006).

Experimental studies using lineage SGS1 to infect different species of passerines have shown that different species respond with different severity level of disease (Palinauskas et al. 2008). Our results appear to be consistent with these findings. For example, a low level of peripheral parasitemia was observed in the kokako and NI saddleback, both members of the family Callaeidae. Conversely, the hihi (family Notiomyslidae) may be highly susceptible to infection, which results in acute parasitemia and death as observed here. The pathology of the hihi described in this study has also been observed in the highly susceptible siskins (Spinus spinus) and crossbills (Loxia curvirostra) (Palinauskas et al. 2008). Hihi are endangered species and it is therefore not possible for experimental infection to be undertaken. However, an examination into the existing lineages of Plasmodium spp. within the hihi breeding populations and a comparison with the lineages that appear to cause mortality could provide additional data to support the speculation about the hihi's sensitivity to specific Plasmodium spp.

Various $P$. (Novyella) spp. have been detected in several species of passerine birds (Paperna et al. 2008; Valkiunas et al. 2009). However, it should be noted that the subgenus Novyella appears to be paraphyletic and that the P. rouxi detected in this study is genetically and morphologically distinct from other subgenus Novyella spp., such as $P$. globularis and $P$. ashfordi, identified around the world (Martinsen et al. 2007; Valkiunas et al. 2009). Several species of Novyella have been shown to be transmitted in Africa. For example, P. (Novyella) ashfordi is known to infect sub-Saharan migrants, such as the great reed warbler in their African wintering grounds (Valkiunas et al. 2007; Zehtindjiev et al. 2008a, b). In addition, within the $P$. (Novyella) rouxi cluster, P. (Novyella) lineages W37 and W38 were isolated from members of the Turdidae family in West Africa (Beadell et al. 2009). It is notable that Plasmodium lineage W37 appears to have a high level of specificity at the avian host species level and together with lineage W38 was a member of a larger clade group, PA (Beadell et al. 2009). Hosts infected with members of clade
PA were also infected by distantly related parasites outside of the large clade group. This suggested that these hosts, such as Turdidae, have been subjected to multiple independent colonization events, a theory supported by this study. Our finding of a kereru (Columbidae) infected with this parasite casts some doubts as to the host specificity of this Plasmodium species and further examination is needed. It is unclear at this time whether members of cluster D have an impact on New Zealand endemic and/or native birds or are restricted to specific hosts, such as the blackbird and pigeon families.

Considering the characteristics of the various Plasmodium species, each of the four cluster groups described in this study may reflect different types of interaction events between the host and parasite. Therefore, the possible effects of these interactions on conservation projects, such as translocations, deserve consideration. In New Zealand, bird translocations are an integral part of re-establishing threatened or endangered bird populations. New Zealand has a long history of successfully using this method in the management of many avian species such as North Island saddlebacks, New Zealand robins, little spotted kiwi and kokako (http://www.massey.ac.nz/ darmstro/nz_projects. $\mathrm{htm})$. However, an increasing number of reports have suggested that avian malaria infections may be restricting the success of some of these programmes (Alley et al. 2008; Alley et al. 2010; Derraik et al. 2008). It has therefore become critical to improve our knowledge on the effect of avian malarial disease, vectors and parasites on native species and to develop appropriate management strategies. These strategies will need to include the identification of regional Plasmodium spp., presence of appropriate vectors and infection prevalence in birds at both the site of origin and the site of translocation. Therefore, the results of this study provide both initial information on host specificity and the potential endemic or introduced origin of the parasite as well as an indication of possible transmission pathways. This information is a critical first step in developing a database which will be useful in predicting and managing avian malaria disease impacts.

Acknowledgements We thank all the people involved in collecting bloods and processing samples, including members of the Massey University Ecology sampling team for sampling on Mokoia Island and Kerri Morgan for sampling kiwi on Ponui Island. Thanks to Megan Willans and other members of the New Zealand Department of Conservation Kokako Translocation team for blood collections on kokako. Thank you also to John Ewen for submitting this dead hihi, Sylvia Durrant of Birdwing for a kereru sample, Dr. Mike Peirce for his assistance in obtaining sequences for kereru and silvereye and Dr. Brett Gartrell for photography of some tissue sections. Our special thanks to The Mokoia Island Trust Board for their continuous support to our project. This project was funded by grants from Massey University Research Fund, the Department of Conservation and Landcare Research in kind contributions. Dr. William Pomroy provided helpful comments to improve this manuscript. 
Open Access This article is distributed under the terms of the Creative Commons Attribution Noncommercial License which permits any noncommercial use, distribution, and reproduction in any medium, provided the original author(s) and source are credited.

\section{References}

Alley MR (2002) Avian wildlife diseases in New Zealand: current issues and achievements. New Zeal Vet J 50(3 Supplement):118120

Alley MR, Fairley RA, Martin DG, Howe L, Atkinson T (2008) An outbreak of avian malaria in captive yellowheads/mohua (Mohoua ochrocephala). New Zeal Vet J 56(5):247-251

Alley MR, Hale KA, Cash W, Ha HJ, Howe L (2010) Concurrent avian malaria and avipox virus infection in translocated South Island saddlebacks (Philesturnus carunculatus carunculatus). New Zeal Vet J 58(4):218-223

Beadell JS, Covas R, Gebhard C, Ishtiaq F, Melo M, Schmidt BK, Perkins SL, Graves GR, Fleischer RC (2009) Host associations and evolutionary relationships of avian blood parasites from West Africa. Int J Parasitol 39(2):257-266

Beadell JS, Ishtiaq F, Covas R, Melo M, Warren BH, Atkinson CT, Bensch S, Graves GR, Jhala YV, Peirce MA, Rahmani AR, Fonseca DM, Fleischer RC (2006) Global phylogeographic limits of Hawaii's avian malaria. P Roy Soc B-Biol Sci 273 (1604):2935-2944

Bennett GF, Peirce MA, Ashford RW (1993) Avian hematozoamortality and pathogenicity. J Nat Hist 27(5):993-1001

Bensch S, Hellgren O, Perez-Tris J (2009) MalAvi: a public database of malaria parasites and related haemosporidians in avian hosts based on mitochondrial cytochrome b lineages. Mol Eco Resour 9(5):1353-1358

Bensch S, Perez-Tris J, Waldenstrom J, Hellgren O (2004) Linkage between nuclear and mitochondrial DNA sequences in avian malaria parasites: multiple cases of cryptic speciation? Evolution 58(7):1617-1621

Castro IC, Howe L, Tompkins DM, Barraclough RK, Slaney D (2011) Presence and seasonal prevalence of Plasmodium spp. in a rare endemic New Zealand passerine (Tieke or saddleback, Philesturnus carunculatus) residing on Mokoia Island, an avian conservation site. J Wildlife Dis 47(4)

Derraik JGB (2004) Exotic mosquitoes in New Zealand: a review of species intercepted, their pathways and ports of entry. Aust NZ J Publ Heal 28(5):433-444

Derraik JGB, Tompkins DM, Alley MR, Holder P, Atkinson T (2008) Epidemiology of an avian malaria outbreak in a native bird species (Mohoua ochrocephala) in New Zealand. J Roy Soc of New Zeal 38(4):237-242

Dore A (1920) The occurrence of malaria in the native ground lark. J Sci Technol 3:118-119

Driskell A, Christidis L, Gill BJ, Boles WE, Barker FK, Longmore NW (2007) A new endemic family of New Zealand passerine birds:adding heat to a biodiversity hotspot. Aust J Zoo 55:73-78

Heather, B. and Robertson, H. (2005) Field Guide to the Birds of New Zealand Revised Edition, Viking

Hellgren O, Krizanauskiene A, Valkiunas G, Bensch S (2007) Diversity and phylogeny of mitochondrial cytochrome B lineages from six morphospecies of avian Haemoproteus (Haemosporida: Haemoproteidae). J Parasitol 93(4):889-896

Hellgren O, Waldenstrom J, Bensch S (2004) A new PCR assay for simultaneous studies of Leucocytozoon, Plasmodium, and Haemoproteus from avian blood. J Parasitol 90(4):797-802

Higgins DG, Thompson JD, Gibson TJ (1994) ClustalW: improving the sensitivity of progressive multiple sequence alignment through sequence weighting, position-specific gap penalties, and weight matrix choice. Nucleic Acids Res 22:4673-4680

Jarvi SI, Farias MEM, Baker H, Freifeld HB, Baker PE, Van Gelder E, Massey JG, Atkinson CT (2003) Detection of avian malaria (Plasmodium spp.) in native land birds of American Samoa. Conserv Genet 4(5):629-637

Kimura M, Darbro JM, Harrington LC (2009) Avian malaria parasites share congeneric mosquito vectors. J Parasitol 96(1):144-151

Laird M (1950) Some blood parasites of New Zealand birds. Zoology publications, vol 5. Victoria University College, Wellington, pp $1-20$

LaPointe DA, Goff ML, Atkinson CT (2005) Comparative susceptibility of introduced forest dwelling mosquitoes in Hawai'i to avian malaria, Plasmodium relictum. J Parasitol 91 (4):843-849

Martinsen ES, Waite JL, Schall JJ (2007) Morphologically defined subgenera of Plasmodium from avian hosts: test of monophyly by phylogenetic analysis of two mitochondrial genes. Parasitology 134:483-490

Massey B, Gleeson DM, Slaney D, Tompkins DM (2007) PCR detection of Plasmodium and blood meal identification in a native New Zealand mosquito. J Vect Ecol 32(1):154-156

Palinauskas V, Kosarev V, Shapoval A, Bensch S, Valkiunas G (2007) Comparison of mitochondrial cytochrome $\mathrm{b}$ lineages and morphospecies of two avian malaria parasites of the subgenera Haemamoeba and Giovannolaia (Haemosporida: Plasmodiidae). Zootaxa 1626:39-50

Palinauskas V, Valkiunas GN, Bolshakov CV, Bensch S (2008) Plasmodium relictum (lineage P-SGS1): effects on experimentally infected passerine birds. Exp Parasitol 120(4):372-380

Paperna I, Yosef R, Chavatte JM, Gill H, Landau I (2008) Species of Plasmodium of passerine birds with four nuclei, with description of new species. Acta Parasitol 53(3):227-236

Ricklefs RE, Fallon SM, Bermingham E (2004) Evolutionary relationships, cospeciation, and host switching in avian malaria parasites. Systematic Biol 53(1):111-119

Ricklefs RE, Outlaw DC (2010) A molecular clock for malaria parasites. Science 329(5988):226-229

Ronquist F, Huelsenbeck JP (2003) MrBayes 3: Bayesian phylogenetic inference under mixed models. Bioinformatics 19:1572-1574

Swofford DL (2002) PAUP*: phylogenetic analysis using parsimony (and other methods) 4.0 Beta, version 10. Sinauer, Sunderland

Tompkins DM, Gleeson DM (2006) Relationship between avian malaria distribution and an exotic invasive mosquito in New Zealand. J Roy Soc New Zeal 36(2):51-62

Valkiunas G (2005) Avian malaria parasites and other haemosporidia. CRC, USA

Valkiunas G, Zehtindjiev P, Hellgren O, Ilieva M, Iezhova TA, Bensch S (2007) Linkage between mitochondrial cytochrome $b$ lineages and morphospecies of two avian malaria parasites, with a description of Plasmodium (Novyella) ashfordi sp nov. Parasitol Res 100(6):1311-1322

Valkiunas G, Atkinson CT, Bensch S, Sehga RNM, Ricklefs RE (2008a) Parasite misidentifications in GenBank: how to minimize their number? Trends Parasitol 24(6):247-248

Valkiunas G, Zehtindjiev P, Dimitrov D, Krizanauskiene A, Iezhova TA, Bensch S (2008b) Polymerase chain reaction-based identification of Plasmodium (Huffia) elongatum, with remarks on species identity of haemosporidian lineages deposited in GenBank. Parasitol Res 102(6): 1185-1193

Valkiunas G, Iezhova TA, Loiseau C, Smith TB, Sehgal RNM (2009) New malaria parasites of the subgenus Novyella in African rainforest birds, with remarks on their high prevalence, classification and diagnostics. Parasitol Res 104(5):1061-1077 
Valkiunas G, Santiago-Alarcon D, Levin II, Iezhova TA, Parker PG (2010) A new Haemoproteus species (Haemosporida: Haemoproteidae) from the endemic galapagos dove Zenaida galapagoensis, with remarks on the parasite distribution, vectors, and molecular diagnostics. J Parasitol 96(4):783-792

Waldenstrom J, Bensch S, Hasselquist D, Ostman O (2004) A new nested polymerase chain reaction method very efficient in detecting Plasmodium and Haemoproteus infections from avian blood. J Parasitol 90(1):191-194

Zehtindjiev P, Ilieva M, Westerdahl H, Hansson B, Valkiunas G, Bensch S (2008) Dynamics of parasitemia of malaria parasites in a naturally and experimentally infected migratory songbird, the great reed warbler Acrocephalus arundinaceus. Exp Parasitol 119 (1):99-110 